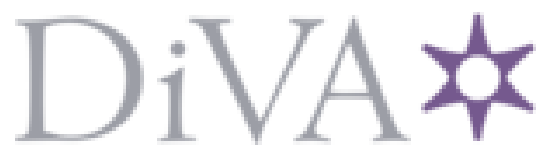

http://www.diva-portal.org

This is the published version of a paper published in BMJ Quality and Safety.

Citation for the original published paper (version of record):

Ogrinc, G., Davies, L., Goodman, D., Batalden, P B., Davidoff, F. et al. (2016)

SQUIRE 2.0 (Standards for QUality Improvement Reporting Excellence): Revised publication guidelines from a detailed consensus process.

BMJ Quality and Safety, 25(12): 986-992

https://doi.org/10.1136/bmjqs-2015-004411

Access to the published version may require subscription.

N.B. When citing this work, cite the original published paper.

Hybrid Open Access article

Permanent link to this version:

http://urn.kb.se/resolve?urn=urn:nbn:se:hj:diva-34697 


\title{
(6) OPEN ACCESS \\ SQUIRE 2.0 (Standards for QUality Improvement Reporting Excellence): revised publication guidelines from a detailed consensus process
}

\author{
Greg Ogrinc, ${ }^{1,2,3}$ Louise Davies, ${ }^{1,2,3}$ Daisy Goodman, ${ }^{1,2}$ Paul Batalden, ${ }^{2,3}$ \\ Frank Davidoff, ${ }^{3}$ David Stevens ${ }^{3,4}$
}

For numbered affiliations see end of article.

\section{Correspondence to}

Dr Greg Ogrinc, Associate Chief of Staff for Education, White River Junction VA, 215 North Main St (111), White River Junction, VT, 05009, USA; greg.ogrinc@med.va.gov

This paper is being co-published in: American Journal of Critical Care, American Journal of Medical Quality, Canadian Journal of Diabetes, Journal of Continuing Education in Nursing, Journal of American College of Surgeons, Journal of Surgical Research, Joint Commission Journal on Quality and Patient Safety, Journal of Nursing Care Quality, The Permanente Journal, GIMBE Evidence for Health (Italy), MedWave (Chile), and Scandinavian Journal of Trauma, Resuscitation, and Emergency Medicine.

Received 19 May 2015 Revised 11 July 2015

Accepted 17 July 2015 Published Online First

25 September 2015

\section{SLinked}

- http://dx.doi.org/10.1136/ bmjqs-2015-004480

CrossMark

To cite: Ogrinc $G$, Davies $L$, Goodman D, et al. BMJ Qual Saf 2016;25:986-992.

\begin{abstract}
Since the publication of Standards for QUality Improvement Reporting Excellence (SQUIRE 1.0) guidelines in 2008, the science of the field has advanced considerably. In this manuscript, we describe the development of SQUIRE 2.0 and its key components. We undertook the revision between 2012 and 2015 using (1) semistructured interviews and focus groups to evaluate SQUIRE 1.0 plus feedback from an international steering group, (2) two face-to-face consensus meetings to develop interim drafts and (3) pilot testing with authors and a public comment period. SQUIRE 2.0 emphasises the reporting of three key components of systematic efforts to improve the quality, value and safety of healthcare: the use of formal and informal theory in planning, implementing and evaluating improvement work; the context in which the work is done and the study of the intervention(s). SQUIRE 2.0 is intended for reporting the range of methods used to improve healthcare, recognising that they can be complex and multidimensional. It provides common ground to share these discoveries in the scholarly literature (http://www.squire-statement.org).
\end{abstract}

In 2005, draft publication guidelines for quality improvement reporting debuted in Quality and Safety in Health Care. ${ }^{1}$ At that time, publications of scholarly work about healthcare improvement were often confusing and of limited value. Leaders in the field were working to consolidate the evidence for a science of improvement ${ }^{2} 3$ and without guidance on how to write their findings, authors struggled to report their improvement work in a reliable and consistent way. ${ }^{45}$ These factors influenced the initial publication in 2008 of the Standards for QUality Improvement Reporting Excellence (SQUIRE), ${ }^{6}$ which we will refer to as SQUIRE 1.0. The guidelines were developed in an effort to reduce uncertainty about the information deemed to be important in scholarly reports of healthcare improvement and to increase the completeness, precision and transparency of those reports.

In the intervening years, the reach of systematic efforts to improve the quality, safety and value of healthcare has grown. Health professionals' education worldwide now includes improvement as a standard competency. ${ }^{7-11}$ The science of the field also continues to advance through guidance on applying formal and informal theory in the development and interpretation of improvement programmes; ${ }^{12}$ stronger ways to identify, assess and describe context; ${ }^{13-16}$ recommendations for clearer, more complete descriptions of interventions ${ }^{17}$ and development of initial guidance on how to study an intervention. ${ }^{18}$

In this setting, we have undertaken a revision of SQUIRE 1.0. When we began, it rapidly became apparent that a wide variety of approaches had developed for improving healthcare, ranging from formative to experimental to evaluative. Rather than limiting the revised guidelines to only a few of these, we fashioned them to be applicable across the many methods that are used. We aimed to reflect the dynamic nature of the field and support its further development. This article describes the development and content of SQUIRE 2.0 (table 1).

\section{SQUIRE 2.0 DEVELOPMENTAL PATH}

We developed SQUIRE 2.0 between 2012 and 2015 in three overlapping phases: (1) evaluation of the initial 
Table 1 Revised Standards for QUality Improvement Reporting Excellence (SQUIRE 2.0) publication guidelines

\section{Text section and item} name

Notes to authors

Section or item description

- The SQUIRE guidelines provide a framework for reporting new knowledge about how to improve healthcare.

- The SQUIRE guidelines are intended for reports that describe system level work to improve the quality, safety and value of healthcare, and used methods to establish that observed outcomes were due to the intervention(s).

- A range of approaches exists for improving healthcare. SQUIRE may be adapted for reporting any of these.

- Authors should consider every SQUIRE item, but it may be inappropriate or unnecessary to include every SQUIRE element in a particular manuscript.

- The SQUIRE glossary contains definitions of many of the key words in SQUIRE.

- The explanation and elaboration document provides specific examples of well-written SQUIRE items and an in-depth explanation of each item.

- Please cite SQUIRE when it is used to write a manuscript.

$\begin{array}{ll}\text { Title and abstract } & \begin{array}{l}\text { Indicate that the manuscript concerns an initiative to improve healthcare (broadly defined to include the quality, safety, } \\ \text { effectiveness, patient-centredness, timeliness, cost, efficiency and equity of healthcare). }\end{array}\end{array}$

2. Abstract a. Provide adequate information to aid in searching and indexing.

b. Summarise all key information from various sections of the text using the abstract format of the intended publication or a structured summary such as: background, local problem, methods, interventions, results, conclusions.

\begin{tabular}{|c|c|}
\hline Introduction & Why did you start? \\
\hline 3. Problem description & Nature and significance of the local problem. \\
\hline 4. Available knowledge & Summary of what is currently known about the problem, including relevant previous studies. \\
\hline 5. Rationale & $\begin{array}{l}\text { Informal or formal frameworks, models, concepts and/or theories used to explain the problem, any reasons or } \\
\text { assumptions that were used to develop the intervention(s) and reasons why the intervention(s) was expected to work }\end{array}$ \\
\hline 6. Specific aims & Purpose of the project and of this report. \\
\hline Methods & What did you do? \\
\hline 7. Context & Contextual elements considered important at the outset of introducing the intervention(s). \\
\hline 8. Intervention(s) & $\begin{array}{l}\text { a. Description of the intervention(s) in sufficient detail that others could reproduce it. } \\
\text { b. Specifics of the team involved in the work. }\end{array}$ \\
\hline 9. Study of the intervention(s) & $\begin{array}{l}\text { a. Approach chosen for assessing the impact of the intervention(s). } \\
\text { b. Approach used to establish whether the observed outcomes were due to the intervention(s). }\end{array}$ \\
\hline 10. Measures & $\begin{array}{l}\text { a. Measures chosen for studying processes and outcomes of the intervention(s), including rationale for choosing } \\
\text { them, their operational definitions and their validity and reliability. } \\
\text { b. Description of the approach to the ongoing assessment of contextual elements that contributed to the success, } \\
\text { failure, efficiency and cost. } \\
\text { c. Methods employed for assessing completeness and accuracy of data. }\end{array}$ \\
\hline 11. Analysis & $\begin{array}{l}\text { a. Qualitative and quantitative methods used to draw inferences from the data. } \\
\text { b. Methods for understanding variation within the data, including the effects of time as a variable. }\end{array}$ \\
\hline 12. Ethical considerations & $\begin{array}{l}\text { Ethical aspects of implementing and studying the intervention(s) and how they were addressed, including, but not limited } \\
\text { to, formal ethics review and potential conflict(s) of interest. }\end{array}$ \\
\hline Results & What did you find? \\
\hline 13. Results & $\begin{array}{l}\text { a. Initial steps of the intervention(s) and their evolution over time (eg, time-line diagram, flow chart or table), } \\
\text { including modifications made to the intervention during the project. } \\
\text { b. Details of the process measures and outcomes. } \\
\text { c. Contextual elements that interacted with the intervention(s). } \\
\text { d. Observed associations between outcomes, interventions and relevant contextual elements. } \\
\text { e. Unintended consequences such as unexpected benefits, problems, failures or costs associated with the } \\
\text { f. Details about missing data. }\end{array}$ \\
\hline
\end{tabular}


Table 1 Continued

\begin{tabular}{|c|c|}
\hline $\begin{array}{l}\text { Text section and item } \\
\text { name }\end{array}$ & Section or item description \\
\hline Discussion & What does it mean? \\
\hline 14. Summary & $\begin{array}{l}\text { a. Key findings, including relevance to the rationale and specific aims. } \\
\text { b. Particular strengths of the project. }\end{array}$ \\
\hline 15. Interpretation & $\begin{array}{l}\text { a. Nature of the association between the intervention(s) and the outcomes. } \\
\text { b. Comparison of results with findings from other publications. } \\
\text { c. Impact of the project on people and systems. } \\
\text { d. Reasons for any differences between observed and anticipated outcomes, including the influence of context. } \\
\text { e. Costs and strategic trade-offs, including opportunity costs. }\end{array}$ \\
\hline 16. Limitations & $\begin{array}{l}\text { a. Limits to the generalisability of the work. } \\
\text { b. Factors that might have limited internal validity such as confounding, bias or imprecision in the design, } \\
\text { methods, measurement or analysis. } \\
\text { c. Efforts made to minimise and adjust for limitations. }\end{array}$ \\
\hline 17. Conclusions & $\begin{array}{l}\text { a. Usefulness of the work. } \\
\text { b. Sustainability. } \\
\text { c. Potential for spread to other contexts. } \\
\text { d. Implications for practice and for further study in the field. } \\
\text { e. Suggested next steps. }\end{array}$ \\
\hline \multicolumn{2}{|l|}{ Other information } \\
\hline 18. Funding & $\begin{array}{l}\text { Sources of funding that supported this work. Role, if any, of the funding organisation in the design, implementation, } \\
\text { interpretation and reporting. }\end{array}$ \\
\hline
\end{tabular}

SQUIRE guidelines, (2) early revisions and (3) pilot testing with late revisions.

We began the evaluation of SQUIRE 1.0 by collecting data to assess its clarity and usability. ${ }^{19}$ Semistructured interviews and focus groups with 29 end users of SQUIRE 1.0 revealed that many found SQUIRE 1.0 helpful in planning and doing improvement work, but less so in the writing process. This issue was especially apparent in the efforts to write about the cyclic, iterative process that often occurs with improvement interventions. SQUIRE 1.0 was seen by many as unnecessarily complex with too much redundancy and lacking a clear distinction between 'doing improvement' and 'studying the improvement'. A recent independent study and editorial also documented and addressed some of these challenges. $^{2021}$

In the second phase, we convened an international advisory group of 18 experts that included editors, authors, researchers and improvement professionals. This group met through three conference calls, reviewed SQUIRE 1.0 and the results of the end-user evaluation, and provided detailed feedback on successive revisions. This advisory group and additional participants attended two consensus conferences in 2013 and 2014 where they engaged in intensive analysis and made recommendations that further guided the revision process.

In the third phase, 44 authors used an interim draft version of the updated SQUIRE guidelines to write sections of a manuscript. Each author then provided comments on the utility and understandability of the draft guidelines, and in their submitted section, identified the portions of their writing samples that fulfilled the items of that section. ${ }^{22}$ We also obtained detailed feedback about this draft version through semistructured interviews with 11 biomedical journal editors. The data from this phase revealed areas needing further clarification, and which specific items were prone to misinterpretation. Finally, a penultimate draft was emailed to over 450 individuals around the world, including the advisory group, consensus meeting participants, authors, reviewers, editors, faculty in fellowship programmes and trainees. This version was also posted on the SQUIRE website with an invitation for public feedback. We used the information from this process to write SQUIRE 2.0 (table 1).

\section{SQUIRE 2.0}

Many publication guidelines, including CONSORT (randomised trials), STROBE (observational studies) and PRISMA (systematic reviews) focus on a particular study methodology (http://www.equator-network. org). In contrast, SQUIRE 2.0 is designed to apply across the many approaches used for systematically improving the quality, safety and value of healthcare. Methods range from iterative changes using plan-dostudy-act cycles in single settings to retrospective analyses of large-scale programmes to multisite randomised trials. We encourage authors to apply other 
publication guidelines-particularly those that focus on specific study methods-along with SQUIRE, as appropriate. Authors should carefully consider the relevance of each SQUIRE item, but recognise that it is sometimes not necessary, nor even possible, to include each item in a particular manuscript.

SQUIRE 2.0 retains the IMRaD (introduction, methods, results and discussion) structure. ${ }^{23}$ Although used primarily for reporting research within a spectrum of study designs, this structure expresses the underlying logic of most systematic investigations, and is familiar to authors, editors, reviewers and readers. We continue to use A. Bradford Hill's four fundamental questions for writing: Why did you start? What did you do? What did you find? What does it mean? ${ }^{24}$ In our evaluation of SQUIRE 1.0, novice authors found these questions to be straightforward, clear and useful.

SQUIRE 2.0 contains 18 items, but omits the multiple subitems that were a source of confusion for SQUIRE 1.0 users. ${ }^{19}$ A range of approaches exists for improving healthcare, and SQUIRE may be adapted for reporting any of these. As stated above, authors should consider every SQUIRE item, but it may be inappropriate or unnecessary to include every SQUIRE item in a particular manuscript. In addition, authors need not use items in the order in which they appear. Major changes between SQUIRE 1.0 and 2.0 are concentrated in four areas: (1) terminology, (2) theory, (3) context and (4) studying the intervention(s).

\section{Terminology}

The elaborate detail in SQUIRE 1.0 was seen by users as both a blessing and a curse ${ }^{19}$ : helpful in designing and executing quality improvement work, but less useful in the writing process. The level of detail sometimes led to confusion about what to include or not include in a manuscript. Consequently, we made the items in SQUIRE 2.0 shorter and more direct.

A major challenge in the reporting of systematic efforts to improve healthcare is the multiplicity of terms used to describe the work, which is challenging for novices and experts alike. Improvement work draws on the epistemology of a variety of fields, and depending on one's field of study, the same words can carry different connotations, a particularly undesirable state of affairs. Terms such as 'quality improvement', 'implementation science' and 'improvement science' refer to approaches that have many similarities, but can also connote important (and often-debated) differences. Other terms such as 'healthcare delivery science', 'patient safety' and even simply 'improvement' are also subject to surprising variation in interpretation. To address this problem in semantics, we created a glossary of terms used in SQUIRE 2.0 (box 1). The glossary provides the intended meaning of certain key terms as we have used them in SQUIRE 2.0 (table 1). These definitions may be helpful in other endeavours, but are not necessarily intended to be adopted for use in other contexts. Overall, we sought terms and definitions that would be useful to the largest possible audience. For example, we chose 'intervention(s)' to refer to the changes that are made. We decided not to use the word 'improvement' in the individual items (although it remains in the SQUIRE acronym) to encourage authors to report efforts that did not lead to changes for the better. Reporting well done, negative studies is vital for the learning in this discipline.

\section{Theory}

SQUIRE 2.0 includes a new item titled 'rationale'. Biomedical and clinical research is driven by iterative cycles of theory building and hypothesis testing. Healthcare improvement work has not consistently based the planning, design and execution of its programmes solidly in theory, to the detriment of the work. For this reason, SQUIRE 2.0 explicitly includes an item devoted to theory, although we chose to use the broader and less technical label 'rationale' to encourage authors to be explicit in reporting formal and informal theories, models, concepts or even hunches as to why they expected a particular intervention to work in a particular context. A plain language interpretation of 'rationale' might be, 'why did you think this would work?' A recent narrative review of the nature of theory and its use in improvement describes the many types and applications of theory, and considers pitfalls in using and not using theory. ${ }^{12}$

The addition of the 'rationale' item is intended to encourage clarity around assumptions about the nature of the intervention, the context and the expected outcomes. The presence of a well thought out rationale will align with appropriate measures and with the study of the intervention; it may also be the starting point for the next round of work. The 'summary' item in the discussion section encourages authors to revisit the original rationale in the light of its findings and in the larger context of similar projects.

\section{Context}

SQUIRE 2.0 accepts 'context' as the key features of the environment in which the work is immersed and which are interpreted as meaningful to the success, failure and unexpected consequences of the intervention(s), as well as the relationship of these to the stakeholders (eg, improvement team, clinicians, patients, families, etc). ${ }^{13-16}$ Systematic efforts to improve healthcare should contain clear descriptions and acknowledgement of context, rather than efforts to control it or explain it away. SQUIRE 1.0 included context with items in all sections of the manuscript, but context did not rise to the level of a distinct item itself. SQUIRE 2.0 recognises context as a fundamental item in the methods section, but its relevance is not limited to this section. In addition to affecting the 
Box 1 Glossary of key terms used in Standards for QUality Improvement Reporting Excellence (SQUIRE) 2.0. This glossary provides the intended meaning of selected words and phrases as they are used in the SQUIRE 2.0 guidelines. They may, and often do, have different meanings in other disciplines, situations and settings

\section{Assumptions}

Reasons for choosing the activities and tools used to bring about changes in healthcare services at the system level.

\section{Context}

Physical and sociocultural make-up of the local environment (eg, external environmental factors, organisational dynamics, collaboration, resources, leadership and the like), and the interpretation of these factors ('sense-making') by the healthcare delivery professionals, patients and caregivers that can affect the effectiveness and generalisability of intervention(s). Ethical aspects

The value of system-level initiatives relative to their potential for harm, burden and cost to the stakeholders. Potential harms particularly associated with efforts to improve the quality, safety and value of healthcare services include opportunity costs, invasion of privacy and staff distress resulting from disclosure of poor performance. ${ }^{25}$

Generalisability

The likelihood that the intervention(s) in a particular report would produce similar results in other settings, situations or environments (also referred to as external validity).

Healthcare improvement

Any systematic effort intended to raise the quality, safety and value of healthcare services, usually done at the system level. We encourage the use of this phrase rather than 'quality improvement', which often refers to more narrowly defined approaches.

\section{Inferences}

The meaning of findings or data, as interpreted by the stakeholders in healthcare services-improvers, healthcare delivery professionals and/or patients and families.

\section{Initiative}

A broad term that can refer to organisation-wide programmes, narrowly focused projects or the details of specific interventions (eg, planning, execution and assessment).

Internal validity

Demonstrable, credible evidence for efficacy (meaningful impact or change) resulting from introduction of a specific intervention into a particular healthcare system.

Intervention(s)

The specific activities and tools introduced into a healthcare system with the aim of changing its performance for the better. Complete description of an intervention includes its inputs, internal activities and outputs (eg, in the form of a logic model) and the mechanism(s) by which these components are expected to produce changes in a system's performance. $^{17}$

\section{Opportunity costs}

Loss of the ability to perform other tasks or meet other responsibilities resulting from the diversion of resources needed to introduce, test or sustain a particular improvement initiative.

\section{Problem}

Meaningful disruption, failure, inadequacy, distress, confusion or other dysfunction in a healthcare service delivery system that adversely affects patients, staff or the system as a whole, or that prevents care from reaching its full potential.

\section{Process}

The routines and other activities through which healthcare services are delivered.

Rationale

Explanation of why particular intervention(s) were chosen, and why it was expected to work, be sustainable and be replicable elsewhere.

Systems

The interrelated structures, people, processes and activities that together create healthcare services for and with individual patients and populations. For example, systems exist from the personal self-care system of a patient to the individual provider-patient dyad system, to the microsystem, to the macrosystem and all the way to the market/social/insurance system. These levels are nested within each other.

Theory or theories

Any 'reason-giving' account that asserts causal relationships between variables (causal theory) or that makes sense of an otherwise obscure process or situation (explanatory theory). Theories come in many forms, and serve different purposes in the phases of improvement work. It is important to be explicit and well founded about any informal and formal theory (or theories) that are used. 
development of the rationale and subsequent design of the intervention(s), context plays a key role in the iterations of intervention(s) and the outcomes. While it is often not simple to capture or describe context, understanding its impact on the design, implementation, measurement and results make it a vital contributor in identifying and reporting the factors and mechanisms responsible for the success or failure of the intervention(s).

\section{Studying the intervention(s)}

The study of the intervention is, perhaps, the most challenging item in SQUIRE. In the evaluation of SQUIRE $1.0^{19}$ and in the pilot testing, ${ }^{22}$ many were perplexed by this item and its subelements. This item was intended to encourage a more formal assessment of the intervention and its associated outcomes. In SQUIRE 2.0, this section is called 'study of the intervention(s)' (table 1).

'Doing' an improvement project is fundamentally different from 'studying' it. The primary purpose of 'doing' improvement is to produce better local processes and outcomes rather than contribute to new generalisable knowledge. In contrast, the reason for 'studying' the intervention is mainly to contribute to the body of knowledge about the efficacy and generalisability of efforts for improving healthcare. Both 'doing' and 'studying' are required for a deep understanding of the nature and impact of the intervention(s) as well as the possible underlying mechanisms. 'Study of the intervention(s)' focuses mainly on whether and why an intervention 'works'. It should align with the rationale and may include, but is not limited to, preplanned formal testing of the proposed theory that the intervention(s) actually produced the observed changes, as well as the impact of the intervention(s) on the context in which the work was done.

SQUIRE 2.0 asks authors to be as transparent, complete and as accurate as possible about reporting 'doing' and 'studying' improvement work as both aspects of the work are key to scholarly reporting. The 'summary' and 'interpretation' items in the discussion encourage authors to explain potential mechanisms by which the intervention(s) resulted (or failed to result) in change, thereby developing explanatory theories that can be subsequently tested.

\section{CONCLUSIONS}

The development of SQUIRE 2.0 consisted of a detailed analysis of SQUIRE 1.0, input from experts in the field and thorough pilot testing. Many methods and philosophical approaches to improve the quality, safety and value of healthcare are available. The systematic efforts to improve healthcare are often complex and multidimensional, and their effectiveness is inherently context dependent. SQUIRE 2.0 provides common ground on which the discoveries contributed by the various approaches can advance the field by sharing them in the published literature.

At the same time, we recognise that simply publishing SQUIRE 2.0 will not effect this change; additional efforts and resources are required. For example, we have created an explanation and elaboration (E\&E) document (Goodman D, Ogrinc G, Davies L; personal communication, 2015) to accompany this article. For each item in SQUIRE 2.0, the E\&E provides one or more examples from the published literature and a commentary on how the example(s) meets or does not meet the item's standards; this information brings the content of each item to life. The SQUIRE website (http://www.squire-statement.org) contains a number of resources in addition to the guidelines themselves, including interactive E\&E pages and video commentaries. The website supports an emerging online community for the continuous use, conversation about and evaluation of the guidelines.

Writing about improvement can be challenging. Sharing successes, failures and developments through scholarly literature is an essential component of the complex work required in order to improve healthcare services for patients, professionals and the public.

Author affiliations

${ }^{1}$ White River Junction VA Medical Center, White River Junction, Vermont, USA

${ }^{2}$ Geisel School of Medicine at Dartmouth, Hanover,

New Hampshire, USA

${ }^{3}$ The Dartmouth Institute for Health Policy and Clinical

Practice, Hanover, New Hampshire, USA

${ }^{4}$ Institute for Healthcare Improvement, Cambridge,

Massachusetts, USA

Acknowledgements This material is based on work supported by the Health Foundation and the Robert Wood Johnson Foundation, and included the use of facilities and material at the White River Junction VA in White River Junction, Vermont, USA.

Collaborators Name and affiliation of members of the SQUIRE 2.0 advisory group: Davina Allen, Cardiff University, UK. Ross Baker, University of Toronto, Canada. Helen Crisp, Health Foundation, UK. Mary Dixon-Woods, University of Leicester, UK. Don Goldmann, Institute for Healthcare Improvement,

USA. Steve Goodman, Stanford University, USA. Leora

Horwitz, New York University, USA. Pam Ironside, Indiana

University, USA. Peter Margolis, University of Cincinnati, USA. Paul Miles, American Board of Pediatrics, USA. Shirley Moore, Case Western Reserve University, USA. Peter Pronovost, Johns Hopkins University, USA. Lisa Rubenstein, University of California Los Angeles, USA. Gwen Sherwood, University of North Carolina, USA. Kaveh Shojania, University of Toronto, Canada. Richard Thomson, Newcastle University, UK. Charles Vincent, Imperial College London, UK. Hub Wollersheim, Radboud University Medical Center, the Netherlands.

Contributors Each member of the author list contributed to the design, execution, writing, editing and approval of this work.

Funding Robert Wood Johnson Foundation (grant number 70024) and Health Foundation (grant number 7099).

\section{Competing interests None.}

Provenance and peer review Not commissioned; externally peer reviewed.

Open Access This is an Open Access article distributed in accordance with the Creative Commons Attribution Non Commercial (CC BY-NC 4.0) license, which permits others to 
distribute, remix, adapt, build upon this work noncommercially, and license their derivative works on different terms, provided the original work is properly cited and the use is non-commercial. See: http://creativecommons.org/licenses/bync/4.0/

\section{REFERENCES}

1 Davidoff F, Batalden P. Toward stronger evidence on quality improvement. Draft publication guidelines: the beginning of a consensus project. Qual Saf Health Care 2005;14:319-25.

2 DeVinney B, ed. Expanding Research and Evaluation Designs to Improve the Science Base for Health Care and Public Health Quality Improvement Symposium. Washington DC: Agency for Health Care Research and Quality. Conference Summary, 15 Sep 2005.

3 Shojania KG, Grimshaw JM. Evidence-based quality improvement: the state of the science. Health Aff (Millwood) 2005;24:138-50.

4 Grol RP, Bosch MC, Hulscher ME, et al. Planning and studying improvement in patient care: the use of theoretical perspectives. Milbank Q 2007;85:93-138.

5 Rubenstein LV, Hempel S, Farmer MM, et al. Finding order in heterogeneity: types of quality-improvement intervention publications. Qual Saf Health Care 2008;17:403-8.

6 Davidoff F, Batalden P, Stevens D, et al. Publication guidelines for quality improvement in health care: evolution of the SQUIRE project. Qual Saf Health Care 2008;17(Suppl 1):i3-9.

7 Batalden P, Leach D, Swing S, et al. General competencies and accreditation in graduate medical education. Health Aff (Millwood) 2002;21:103-11.

8 Interprofessional Education Collaborative Expert Panel. Core Competencies for Interprofessional Collaborative Practice: Report of an Expert Panel. Washington DC: Interprofessional Education Collaborative, 2011.

9 Teaching for Quality. 2013. https://www.aamc.org/initiatives/cei/ te4q/ (accessed 21 Jun 2013).

10 Cronenwett L, Sherwood G, Barnsteiner J, et al. Quality and safety education for nurses. Nurs Outlook 2007;55:122-31.

11 Nasca TJ, Philibert I, Brigham T, et al. The next GME accreditation system-rationale and benefits. N Engl J Med 2012;366:1051-6.

12 Davidoff F, Dixon-Woods M, Leviton L, et al. Demystifying theory and its use in improvement. BMJ Qual Saf 2015;24:228-38.
13 Bate P, Robert G, Fulop N, et al. Perspectives on context. London: The Health Foundation, 2014.

14 Kaplan HC, Provost LP, Froehle CM, et al. The Model for Understanding Success in Quality (MUSIQ): building a theory of context in healthcare quality improvement. BMJ Qual Saf 2012;21:13-20.

15 Øvretveit J. Understanding the conditions for improvement: research to discover which context influences affect improvement success. BMJ Qual Saf 2011;20(Suppl 1): i18-23.

16 Taylor SL, Dy S, Foy R, et al. What context features might be important determinants of the effectiveness of patient safety practice interventions? BMJ Qual Saf 2011;20: 611-17.

17 Hoffmann TC, Glasziou PP, Boutron I, et al. Better reporting of interventions: template for intervention description and replication (TIDieR) checklist and guide. BMJ 2014;348:1-12.

18 Portela MC, Pronovost PJ, Woodcock T, et al. How to study improvement interventions: a brief overview of possible study types. BMJ Qual Saf 2015;24:325-36.

19 Davies L, Batalden P, Davidoff F, et al. The SQUIRE guidelines: an evaluation from the field, 5 years post release. BMJ Qual Saf 2015;24:765-75.

20 Howell V, Schwartz AE, O'Leary JD, et al. The effect of the SQUIRE (Standards of QUality Improvement Reporting Excellence) guidelines on reporting standards in the quality improvement literature: a before-and-after study. BMJ Qual Saf 2015;24:400-6.

21 Stevens D. SQUIRE and the evolving science of healthcare improvement. BMJ Qual Saf 2015;24:349-51.

22 Davies L, Donnelly K, Goodman D, et al. Findings from a novel approach to publication guideline revision: User road testing of a draft version of SQUIRE 2.0. BMJ Qual Saf 2015;25:265-72.

23 Day RA. The origins of the scientific paper: the IMRaD format. J Am Med Writers Assoc 1989;4:16-18.

24 Huth E. Writing and publishing in medicine. 3rd edn. Baltimore: Williams and Wilkins, 1999.

25 Baily M, Bottrell M, Lynn J, et al. Special report: the ethics of using QI methods to improve health care quality and safety. Hastings Center Rep 2006;34:s1-40. 
BMJ Quality

\& Safety

SQUIRE 2.0 (Standards for QUality

Improvement Reporting Excellence) : revised publication guidelines from a detailed consensus process

Greg Ogrinc, Louise Davies, Daisy Goodman, Paul Batalden, Frank Davidoff and David Stevens

BMJ Qual Saf 2016 25: 986-992 originally published online September 14,2015

doi: 10.1136/bmjqs-2015-004411

Updated information and services can be found at:

http://qualitysafety.bmj.com/content/25/12/986

\section{These include:}

References This article cites 20 articles, 12 of which you can access for free at: http://qualitysafety.bmj.com/content/25/12/986\#BIBL

Open Access This is an Open Access article distributed in accordance with the Creative Commons Attribution Non Commercial (CC BY-NC 4.0) license, which permits others to distribute, remix, adapt, build upon this work non-commercially, and license their derivative works on different terms, provided the original work is properly cited and the use is non-commercial. See: http://creativecommons.org/licenses/by-nc/4.0/

Email alerting Receive free email alerts when new articles cite this article. Sign up in the service box at the top right corner of the online article.

Topic Articles on similar topics can be found in the following collections Collections

\section{Notes}

To request permissions go to:

http://group.bmj.com/group/rights-licensing/permissions

To order reprints go to:

http://journals.bmj.com/cgi/reprintform

To subscribe to BMJ go to:

http://group.bmj.com/subscribe/ 